\title{
Cellulosic biomass could help* meet California's transportation fuel needs
}

by Charles E. Wyman and Bin Yang

Cellulosic biomass, which includes agricultural and forestry residues and woody and herbaceous plants, is the only low-cost resource that can support the sustainable production of liquid fuels on a large enough scale to significantly address our transportation energy needs. The biological conversion of cellulosic biomass to ethanol could offer high yields at low costs, but only if we can improve the technology for releasing simple sugars from recalcitrant biomass. We review key aspects of cellulosic ethanol production, including pretreatment and enzymatic hydrolysis technologies that present the greatest opportunities to lower processing costs. Although several companies seek to introduce cellulosic ethanol commercially, innovative measures are needed to help overcome the perceived risks of first applications.

ellulosic biomass, a structural material in plants that can be converted into ethanol, is the only large-scale sustainable resource for producing alternative liquid fuels that can be integrated with our existing transportation infrastructure. Cellulosic biomass includes agricultural residues such as corn stover (the corn plant minus kernels and roots), forestry residues such as sawdust and paper, yard waste from municipal solid waste, herbaceous plants such as switchgrass, and woody plants such as poplar trees. Because a dry ton of cellulosic biomass could provide about three times as much energy as a barrel of petroleum, cellulosic biomass would be worth about $\$ 200$ per dry ton when crude oil sells at $\$ 65$ per barrel. It can be purchased for about a third of that amount. To utilize this abundant resource, we must develop low-cost tech-

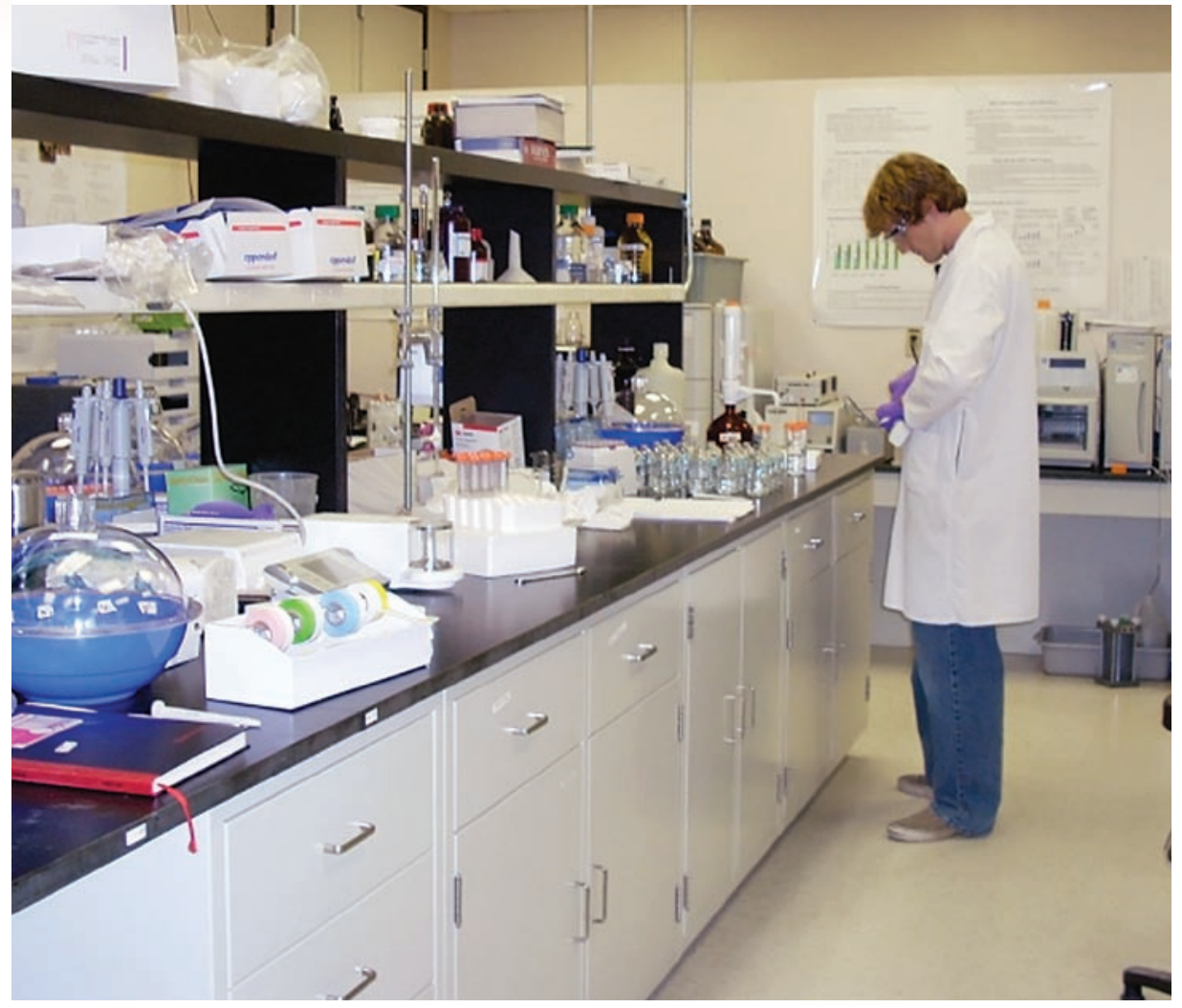

Laboratories at the Center for Environmental Research and Technology at UC Riverside focus on understanding and improving pretreatment, enzymatic hydrolysis and fermentation technologies for the biological conversion of cellulosic biomass into ethanol and other products.

nologies for transforming biomass into fuels that can compete with petroleum (Lynd et al. 1999).

The U.S. Department of Agriculture and Department of Energy (DOE) project that nationwide about 1.3 billion dry tons of cellulosic biomass (equivalent to 1.5 billion barrels of petroleum) could be available annually nationwide, enough for a major impact on energy use (Perlack et al. 2005), and that largescale biomass use is possible without threatening food supplies (Lynd et al. 2007). Overall, the conversion of cellulosic biomass into ethanol and other organic liquid fuels can improve energy security, reduce trade deficits, enhance global competitiveness and create rural employment. In addition, biotechnology can be harnessed to further reduce costs and realize the high yields vital to economic success (Wyman 1994). Perhaps of greatest importance, when appropriately utilized, cellulosic ethanol can release very little if any net carbon dioxide, because carbon dioxide released during processing and combustion only slightly exceeds the amount sequestered by cellulosic biofuel feedstocks such as trees and grasses. This provides a powerful and not readily matched mechanism to cut greenhouse-gas emissions due to transportation, the largest U.S. contributor with about a third of the total (Farrell et al. 2006).

Both President Barack Obama and his predecessor in the White House have identified production of ethanol from cellulosic materials such as switchgrass and wood as vital to overcoming the U.S. "addiction" to oil. In recent years, California also adopted several bold new initiatives, including: (1) AB32, The Global Warming Solutions 
Act of 2006, which caps greenhouse-gas emissions at 1990 levels by 2020, (2) an executive order establishing the first Low Carbon Fuel Standard and calling for a reduction in the carbon intensity of passenger-vehicle fuels by at least $10 \%$ by 2020, and (3) an historic agreement with Arizona, New Mexico, Oregon and Washington to reduce greenhousegas emissions through a market-based approach. Meeting these targets will be challenging for a state with a transportation fuels market that dwarfs that of other states. Transportation fuels ac-

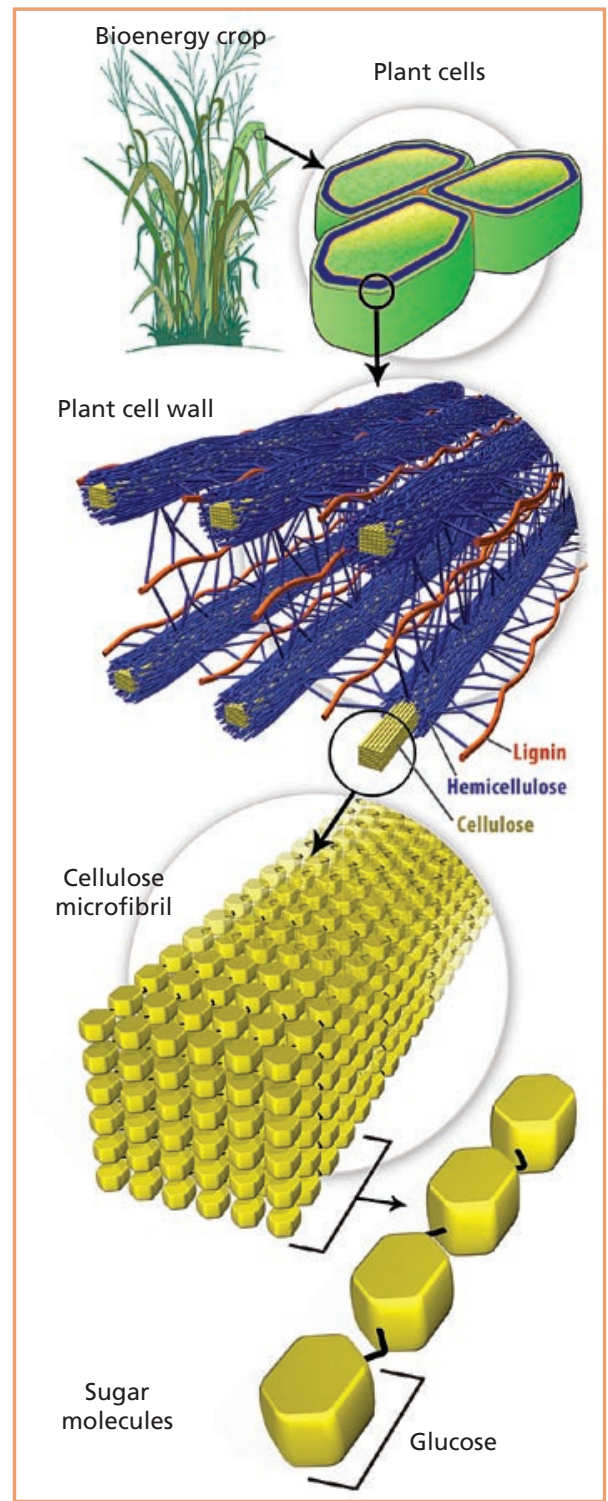

Fig. 1. Lignocellulose, the most abundant organic substance on Earth, is composed of three major constituents - cellulose, hemicellulose and lignin - that combine to protect energy-storing sugars and give the plant cell wall strength and structure. Source: Genome Management Information System, Oak Ridge National Laboratory. count for about $40 \%$ of California's total energy use; the state is the largest transportation fuels market in the country. Additionally, about $40 \%$ of California's greenhouse-gas emissions come from transportation, a higher fraction than the country as a whole.

At present, cellulosic biomass is the only environmentally sustainable resource for producing liquid transportation fuels to meet these goals. California has large quantities of agricultural residues, forest thinnings and residues, and municipal waste. The California Biomass Collaborative estimates that the state produces about 24.2 million dry tons of cellulosic biomass annually, with enough of this available for the sustainable production of fuels displacing about 1.1 billion gallons of gasoline each year (http://biomass.ucdavis.edu).

\section{Cellulosic biomass composition}

Cellulosic biomass has three major components: hemicellulose, cellulose and lignin. Hemicellulose is an amorphous, branched polymer that is usually composed primarily of five sugars (arabinose, galactose, glucose, mannose and xylose); it typically comprises about $15 \%$ to $30 \%$ of cellulosic biomass. Cellulose is a large, linear polymer of glucose molecules typically joined together in a highly crystalline structure due to hydrogen bonding between parallel chains; it typically comprises about $35 \%$ to $50 \%$ of cellulosic biomass. Lignin is a complex phenyl-propane polymer that often comprises about $15 \%$ to $30 \%$ of cellulosic biomass. Although lignin cannot be converted into fermentable sugars, this component has high value as a boiler fuel and could also be useful as a raw material for making aromatic compounds such as benzene and toluene.

\section{Turning biomass into fuel}

The biological processing of cellulosic biomass involves first using enzymes as catalysts to release sugars, as in from hemicellulose and cellulose by hydrolysis (in which water reacts with these fractions to release simple sugars), and then using microorganisms to ferment the sugars into ethanol (fig. 1). In laboratory studies, the enzyme-catalyzed hydrolysis of cellulose into glucose is promising for making fuel or other commodities because high glucose yields, considered vital to economic success, are possible (US DOE 1993).

The costs of processing cellulosic biomass have already been reduced by about a factor of four in the last 25 years, making them competitive with costs for producing ethanol from corn (Wyman 2001). Many of the advances needed to lower costs further are achievable through the application of powerful, evolving tools of biotechnology (Lynd et al. 2008). In addition, the high selectivity of biological processing, particularly of enzymes that catalyze reactions, minimizes waste generation and related disposal problems.

Acid processing. Dilute acids can also break down cellulose into simple sugars. However, they have two drawbacks: (1) in commercially practical processes, glucose yields are limited to $50 \%$ to $60 \%$ of those theoretically possible, and (2) the degradation products cause operational problems. (Cao et al. 1997). Concentrated acids achieve more commercially attractive yields because hydrolysis occurs at relatively low temperatures and pressures. However, acid recovery is expensive, and must be improved to attain competitive costs with plentiful feedstocks (Cao et al. 1997).

Enzymatic processing. To overcome the natural resistance of cellulose to biological degradation, biomass is milled and pretreated. Pretreatment with dilute acid often achieves hemicellulose sugar yields of up to $90 \%$ and makes the cellulose left in the solids highly digestible by enzymes. The resulting liquid is treated to remove inhibitory compounds such as acetic acid, which would otherwise interfere with enzymes such as cellulase. Inhibitory compounds are naturally released from biomass, as in acetic acid, or may be formed by its degradation, as in furfural, a chemical used to make plastic materials. This sugar stream is fermented using technology developed to convert the five 5-carbon hemicellulose sugars into ethanol.

The second sugar stream is derived by adding the enzyme cellulase to pretreated solids. This catalyzes cellulose breakdown with glucose yields of over 90\% for appropriate cellulase formulations and pretreatment conditions; many organisms, including common yeast, can ferment glucose into ethanol at around $90 \%$ of theoretical yields. 

portation fuels on a large scale and at low cost.

Ethanol and other products. Finally, the fermentation broth from both sugar streams is transferred to distillation columns, then to molecular sieves to concentrate and recover the ethanol. Lignin, water, enzymes, microorganisms and other nonethanol components are left in the column bottoms, and are concentrated to feed a boiler that provides heat and electricity for the entire process. Finally, excess electricity is sold. Liquid not retained with the solids is treated, and the resulting clean water is discharged or recycled. The sludge is disposed of, any methane produced is fed to a boiler, and ash is landfilled. Coupling the use of lignin for boiler fuel with the low levels of fertilizer needed to grow cellulosic crops, fossil energy inputs are minimal, and the net release of carbon dioxide is low (Farrell et al. 2006).

\section{Pretreatment options}

Pretreatment can provide two vital functions: recovering sugars from the hemicellulose, and improving the enzyme digestion of cellulose into glucose. Innovative pretreatments could also recover lignin, protein, minerals, oils and other materials in biomass to enhance revenues (Lynd et al. 1999). Pretreatment is projected to be the most costly operation in the conversion of biomass to ethanol, representing about one-third of total processing costs, and it substantially affects upstream and downstream operations (for instance, if acetic acid or furfural build up and inhibit biomass degradation or fermentation). However, costs are even higher without pretreatment; we believe that the only operation more expensive than pretreatment is no pretreatment (Wyman 2007).

Our understanding of how pretreatment technology deconstructs biomass is confounded by the fact that a hemicellulose-and-lignin shield surrounds cellulose, limiting its accessibility (Hsu 1996). Yet, little effort has been spent on thoroughly understanding pretreatment, resulting in trial-and-error approaches and impeding progress toward lower costs.

Over the years, various biological, chemical and physical pretreatments have been applied to enhance the susceptibility of cellulose to attack by enzymes, and to recover hemicellulose sugars with high yields (Hsu 1996). Ammonia, lime, controlled $\mathrm{pH}$, sulfur dioxide and dilute sulfuric acid are cost-effective pretreatments, and they are being studied by the Biomass Refining Consortium for Applied

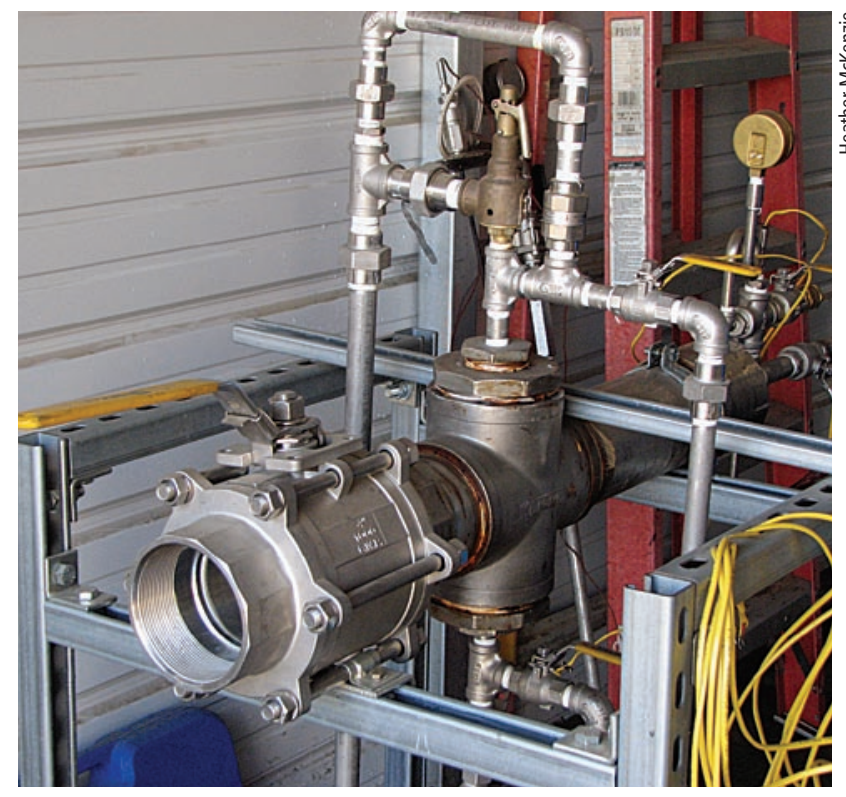

Researchers at UC Riverside invented this novel steam chamber, which heats up the reactors used to pretreat biomass more quickly and uniformly, and, conversely, cools down the material more rapidly than previous technology allowed.

Fundamentals and Innovation (a national consortium of universities and the DOE National Renewable Energy Laboratory) for applications to corn stover, poplar wood and switchgrass (Wyman et al. 2005).

Dilute sulfuric acid hydrolysis has been the subject of considerable research and development, particularly targeting fuels production. Hemicellulose sugar yields from uncatalyzed steam explosion are limited to about $65 \%$ (Heitz et al. 1991), but adding dilute sulfuric acid can enhance yields by $50 \%$ and produce more digestible cellulose at relatively low cost (Knappert et al. 1981). The technology is also effective for a variety of feedstocks. For example, sugar yields of $85 \%$ to $90 \%$ or even more can be recovered from hemicellulose with temperatures of around $320^{\circ} \mathrm{F}\left(160^{\circ} \mathrm{C}\right)$, reaction times of about 10 minutes and acid levels of about $0.5 \%$ (Lloyd and Wyman 2005). About $85 \%$ to $90 \%$ of the remaining cellulose can then be enzymatically digested into glucose (Lloyd and Wyman 2005). The National Renewable Energy Laboratory in Golden, Colo., and others favor dilute sulfuric acid hydrolysis for near-term applications.

Because it is corrosive, however, dilute sulfuric acid hydrolysis is still expensive, requiring costly construction materials for processing equipment. Its degradation products (such as furfural and lignin fragments) and solubilized biomass compounds (such as acetic acid) must be removed before fermentation by processes such as overliming or ion exchange. In addition, acid neutralization and hydrolyzate conditioning with lime both form gypsum, which causes downstream difficulties. Furthermore, the cost of sulfuric acid and lime mount when accounting for disposal costs following neutralization.

\section{Hydrolysis and fermentation}

Enzymatic hydrolysis. A major challenge for cellulosic ethanol has been improving the technology for hydrolysis of recalcitrant cellulose, with high glucose yields made possible by the synergistic action of three classes of fungal cellulase components: endoglucanase, cellobiohydrolase and beta-glucosidase. Classical mutations of the cellulase-producing fungus Trichoderma reesei, which was discovered during World War II, improved the enzymes by, for example, enhancing beta-glucosidase activity for converting cellobiose, a powerful inhibitor, into glucose. (Cellobiose is two chemically bonded glucose molecules that slow further breakdown of cellulose.) In addition, cellulase evolved from earlier strains of $T$. reesei such as QM9414, to improved varieties such as Rut C30 (Kadam 1996; Montencourt and Kelleher 1980) and Genencor 150L 
Cellulosic biomass includes a range of plant materials that can be converted into ethanol for use as liquid transportation fuel. Right, a border of switchgrass, an herbaceous plant that shows promise as a biofuel.

(Wyman et al. 1986). Genencor and Novozymes announced significant progress in reducing enzyme costs through DOE support (CEN 2005; CEP 2004). Although uncertainty remains regarding the actual commercial price, several new projects are being funded by DOE to drop costs even further.

\section{Saccharification and fermentation}

The glucose released when cellulose is broken down by cellulase is a powerful inhibitor of this enzyme. To reduce glucose accumulation during cellulose breakdown (or saccharification), yeast or another fermentative organism can be added to convert the released sugars into ethanol. This configuration is called simultaneous saccharification and fermentation (SSF). Compared to hydrolysis alone, SSF offers better rates, yields and concentrations of ethanol, although at lower temperatures than are optimal for enzymes.

Following identification of the SSF configuration in the mid-1970s (Takagi et al. 1977), fermentative organisms were sought to tolerate the combined stresses of (1) higher temperatures, to increase hydrolysis rates by enzymes, (2) low glucose levels, due to rapid sugar metabolism by the fermentative organism and (3) high ethanol concentrations, which are lethal to fermentative organisms (Wyman et al. 1986).

SSF performance was improved by the yeast Brettanomyces custersii, which ferments cellobiose directly into ethanol, or by coculturing the less-ethanoltolerant yeast $B$. claussenii with the more robust Saccharomyces yeast (Spindler et al. 1992). Similar benefits are provided by bacteria genetically engineered to ferment xylose (one of the sugars derived from hemicellulose) into ethanol, bacteria that ferment cellobiose into ethanol either naturally or through genetic modifications, and organisms that also make cellulase components (Wood and Ingram 1992). The search continues for temperature tolerance and other traits that better match the operating conditions preferred by cellulase.

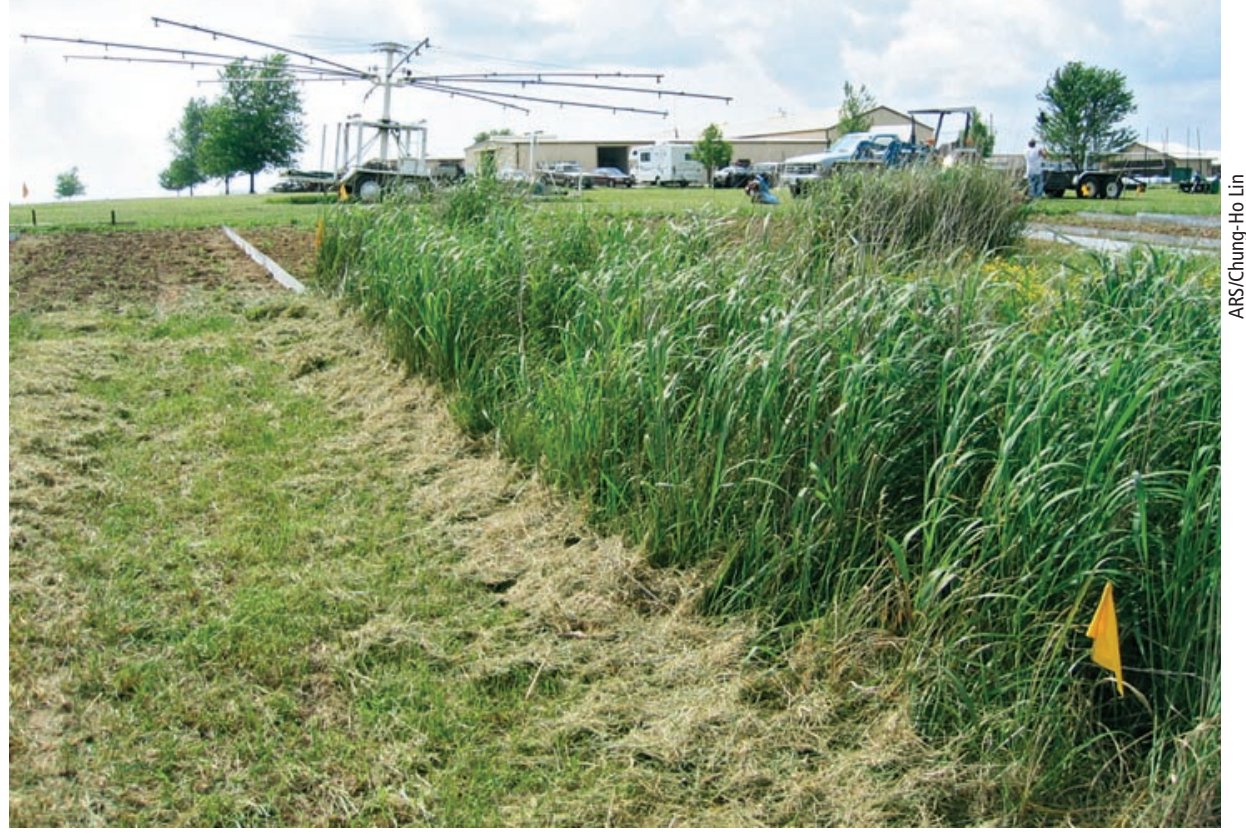

Since the early studies, SSF has been applied to a wide range of feedstocks pretreated under various conditions (Ballesteros et al. 2002), including a few applications in fed-batch and continuous processes for the conversion of paper sludge and wood. SSF has been combined with hemicellulose sugar fermentation (simultaneous saccharification and cofermentation) to lower costs, and has been studied for making products other than ethanol (Thomas 2000). Other approaches are still being considered (Alkasrawi et al. 2002), but SSF technology is a leading candidate for near-term applications and will likely remain so until cellulases can act much faster (that is, make it possible to perform two steps as fast as SSF performs one) with minimal product inhibition at high temperatures (Wright et al. 1987).

Numerous laboratory experiments are focusing on batch operations for enzymatic hydrolysis or SSF, as well as limited fed-batch or continuous systems. Surfactants can improve performance (reduce the amount of enzyme needed to yield the same amount of ethanol) (Castanon and Wilke 1981), and the addition of protein can enhance glucose yields by reducing the nonproductive binding of enzymes to lignin (Yang and Wyman 2004, 2006). This approach can also reduce or eliminate the current practice of supplementing cellulose processing with beta-glucosidase to keep cellobiose concentrations from inhibiting enzyme activity. Nonetheless, even at costly enzyme doses of 15 international filter paper units per gram (IU/g) of cellulose, typical SSF reaction times are about 5 to 7 days to achieve modest ethanol concentrations (Kadam et al. 2004)

\section{Economics of cellulosic ethanol}

Projected costs. Although estimates always suffer from inaccuracies, economic models can track progress, identify promising options and define lower cost paths. Researchers project that cellulosic ethanol costs have dropped from about $\$ 4$ to $\$ 5$ per gallon of ethanol in 1980 to be competitive with corn ethanol (which today costs close to $\$ 1$ per gallon to produce), and commercial projects are now under way (Wyman 1999). These cost reductions can be attributed to progress in two areas: (1) overcoming biomass recalcitrance through advances in pretreatment, cellulases and fermentation integration (SSF) (Wyman 2001), and (2) overcoming biomass sugar diversity by fermenting all five hemicellulose-derived sugars into ethanol with high yields (Ho et al. 1998; Ingram et al. 1999). Cellulase enzymes have historically been a key cost, because of the large amounts required. Major cellulase cost reductions have been claimed by producers, but the current purchase price for initial applications is unclear, clouding decisions on commercial status and research needs. One way to reduce enzyme costs would be to produce cellulase on-site (Himmel et al. 1999).

Commercial challenges. Several companies are attempting to commercialize cellulosic ethanol in the United States, including Broin, BlueFire, Dupont, Iogen, Mascoma, SWAN Biomass and Verenium (CEN 2007). Because the tech- 
nology is unproven commercially and is capital intensive, strategies such as capitalizing on low-cost waste materials, integrating with existing facilities, utilizing tax-free bonds and developing higher-margin coproducts (such as succinic acid) are needed to overcome risk concerns (Wyman and Goodman 1993). The three most-expensive process steps are projected to be pretreatment, enzymatic hydrolysis and enzyme production, in that order, which means that enhancing performance and reducing costs will depend on integrating these steps more effectively.

\section{Reducing costs}

Of the total cost of cellulosic ethanol production, the four most expensive elements are projected to be feedstocks $(33 \%)$, pretreatment $(18 \%)$, enzymatic hydrolysis (12\%) and enzyme production (9\%) (Wooley et al. 1999). However, because biomass unit energy costs are equivalent to those of oil at about \$20 per barrel (Lynd et al. 1999), these factors are the major drivers for large cost reductions in unit operations to overcome the recalcitrance of biomass (Wyman 2007). Consequently, total cel-

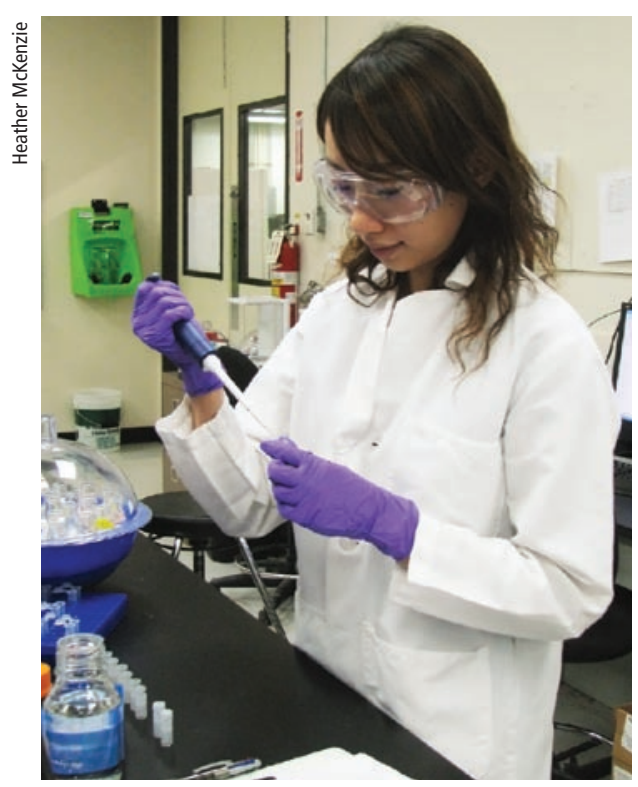

UC Riverside Ph.D. student Qing Qin uses a pipette to measure enzymatic hydrolysis samples into vials, in order to determine sugar concentrations. This research ultimately seeks more efficient ways to break down plant cellulose into sugars that can be fermented into transportation fuel. lulosic ethanol costs could be competitive with other fuels without subsidies via further advances in pretreatment and the integration of enzyme production, enzymatic hydrolysis and fermentation (Lynd et al. 2008). Biomass at $\$ 60$ per dry ton realistically yields about 100 gallons of ethanol, which translates into a feedstock cost of only 60 cents per gallon. The challenge is to advance technologies so that feedstock represents more than two-thirds of the final product cost, as is typical for mature commodity businesses, resulting in a cellulosic ethanol cost of about 90 cents per gallon or less. Other keys to reducing costs are minimizing processing vessel sizes, reducing the cost of construction materials, reducing the number of process steps, avoiding high pressures and temperatures, improving thermal integration (using residual heat from one process step to meet the needs of another step of the process), and lowering power requirements and water use.

"Consolidated bioprocessing" is a promising approach — organisms produce powerful enzymes anaerobically and ferment all of the sugars released into ethanol, with high yields. Modern biotechnology offers great potential for the development of new organisms to accomplish such feats, and great strides have already been made (for instance, in the genetic engineering of microorganisms to ferment arabinose and xylose into ethanol). Pretreatment costs could also be decreased with advances such as lower chemical use and milling demand, less-expensive construction materials, decreased sugar degradation, lower inhibitor formation, and higher hemicellulose and cellulose sugar yields (Lynd et al. 2008).

\section{Refining coproducts}

A range of fuels, chemicals and natural materials could be derived biologically from the sugar intermediates used to make ethanol in a biorefinery, as is done with petroleum, corn and other commodities (Lynd et al. 1999). Several analyses point out that the biological conversion of cellulosic biomass benefits from economies of scale, with all unit costs going down as scale increases and boiler, power generation and waste treatment costs dropping fastest (Wooley et al. 1999). Furthermore, although the costs to transport feedstock increase with distance, capital cost reductions are projected to outweigh these until more than about 10,000 dry tons per day of feedstock is used. Few chemical markets can currently support such large facilities, but ethanol has the huge market demand for which they are appropriate.

Coproduction of small-volume chemicals would increase the profitability of a large-scale biomass facility because side streams of low-cost sugars resulting from cellulosic ethanol production could be converted into products such as succinic acid that have greater margins. Similarly, the excess power produced from burning lignin and other residues could be sold into the grid at lower prices than are possible for a dedicated power plant. Lignin could also be used as a precursor for the production of aromatic compounds and various natural materials. Cellulosic biomass contains valuable constituents including oils, proteins, minerals and complex materials valuable in processing (Dale 1983), and the extraction of such components through biorefining could enhance the range of products and associated financial benefits. On the other hand, introducing multiple products increases the technical risks of a venture and provides additional marketing challenges. Focusing on a single product first is prudent, with add-ons later to diversify the product slate and increase profitability.

\section{Commercial production}

The need for sustainable energy production to address mounting security and environmental problems is finally being recognized, and cellulosic biomass is the only known resource for the sustainable production of liquid transportation fuels on a large scale and at low cost. Cellulosic fuels such as ethanol would be particularly beneficial for California to meet its bold new initiatives to reduce greenhouse-gas emissions, and the state has abundant cellulosic resources. 
Substantial advances in the enzymatic hydrolysis of cellulosic biomass into sugars and their fermentation into ethanol make the technology attractive now, and even lower costs are forecast as the technology matures, although particular attention is needed to advance pretreatment systems and assure that low-priced enzymes are available. The primary challenge for the first commercial market entries is overcoming the perceived risk for such capital-intensive projects, and innova-

\section{References}

Alkasrawi M, Galbe M, Zacchi G. 2002. Recirculation of process streams in fuel ethanol production from softwood based on simultaneous saccharification and fermentation. Appl Biochem Biotechnol 98:849-61.

Ballesteros I, Oliva JM, Negro MJ, et al. 2002. Ethanol production from olive oil extraction residue pretreated with hot water. Appl Biochem Biotechnol 98:717-32.

Cao NJ, Xia YK, Gong CS, Tsao GT. 1997. Production of 2,3-butanediol from pretreated corn cob by Klebsiella oxytoca in the presence of fungal cellulase. Appl Biochem Biotechnol 63(5):129-39.

Castanon M, Wilke CR. 1981. Effects of the surfactant Tween-80 on enzymatic-hydrolysis of newspaper. Biotechnol Bioengin 23(6):1365-72

[CEN] Chemical and Engineering News. 2005. Novozymes, DOE claim cost cut. American Chemical Society, Washington, DC. April 18, 2005. p 10.

CEN. 2007. DOE doubles biorefinery grants. American Chemical Society, Washington, DC. March 5 , 2007. $p 46$.

[CEP] Chemical Engineering Progress. 2004. Genencor makes strides in the conversion of biomass to ethanol. American Institute of Chemical Engineers, New York, NY. p 15.

Dale BE. 1983. Biomass refining - protein and ethanol from alfalfa. Industr Eng Chem Product Res Dev 22(3):466-72.

Farrell AE, Plevin RJ, Turner BT, et al. 2006. Ethanol can contribute to energy and environmental goals. Science 311:506-8

Heitz M, Capek-Menard E, Koeberle PG, et al. 1991. Fractionation of Populus tremuloides at the pilot plant scale: Optimization of steam pretreatment using Stake II technology. Biores Technol 35:23-32.

Himmel ME, Ruth MF, Wyman CE. 1999. Cellulase for commodity products from cellulosic biomass. Curr Op Biotechnol 10(4):358-64

Ho NWY, Chen ZD, Brainard AP. 1998. Genetically engineered saccharomyces yeast capable of effective cofermentation of glucose and xylose. Appl Env Microbiol 64(5):1852-9.

Hsu TA. 1996. Pretreatment of biomass. In: Wyman CE (ed.). Handbook on Bioethanol, Production and Utilization. Washington, DC: Taylor Francis. p 179-212. tive approaches will be needed for success. Once in place, the low-cost sugars from making ethanol at a large scale can support the profitable production of other products from cellulosic biomass, including sugar intermediates, residue-based power, lignin derivatives and natural materials.

\section{C.E. Wyman is Ford Motor Company Chair in} Environmental Engineering, Center for Environmental Research and Technology (CE-CERT),

Ingram LO, Aldrich HC, Borges ACC, et al. 1999. Enteric bacterial catalysts for fuel ethanol production. Biotechnol Progr 15(5):855-66.

Kadam KL. 1996. Cellulase production. In: Wyman CE (ed.). Handbook on Bioethanol, Production and Utilization. Washington, DC: Taylor Francis. p 213-52.

Kadam KL, Rydholm EC, McMillan JD. 2004. Development and validation of a kinetic model for enzymatic saccharification of lignocellulosic biomass. Biotechnol Progr 20(3):698-705.

Knappert DR, Grethlein HE, Converse AO. 1981. Partial acid hydrolysis of poplar wood as a pretreatment for enzymatic hydrolysis. Biotechnol Bioengin Symp 11:67-77.

Lloyd TA, Wyman CE. 2005. Total sugar yields for pretreatment by hemicellulose hydrolysis coupled with enzymatic hydrolysis of the remaining solids. Biores Techno 96(18):1967-77

Lynd LR, Laser MS, Bransby D, et al. 2008. How biotech can transform biofuels. Nat Biotechnol 26(2):169-72.

Lynd LR, Laser M, McBride J, et al. 2007. Energy myth three - high land requirements and an unfavorable energy balance preclude biomass ethanol from playing a large role in providing energy services. In: Sovacool B, Brown M (eds.). Energy and American Society - Thirteen Myths. New York, NY: Springer. 371 p.

Lynd LR, Wyman CE, Gerngross TU. 1999. Biocommodity engineering. Biotechnol Progress 15:777-93.

Montencourt BS, Kelleher TJ. 1980. Biochemical nature of cellulases from mutants of Trichoderma reesei. Biotechnol Bioengin Symp 10:15-26.

Perlack R, Wright L, Turhollow A, et al. 2005. Biomass as Feedstock for a Bioenergy and Bioproducts Industry: The Technical Feasibility of a Billion-Ton Annual Supply. Oak Ridge National Laboratory, Oak Ridge, TN. Rep \#A357634.

Spindler DD, Wyman CE, Grohmann K, Philippidis GP. 1992. Evaluation of the cellobiose-fermenting yeast Brettanomyces custersii in the simultaneous saccharification and fermentation of cellulose. Biotechnol Letters 14(5):403-7.

Takagi M, Abe S, Suzuki S, et al. 1977. A method for production of alcohol directly from cellulose using cellulase and yeast. In: Emert GH, Yata N (eds.). Proc Bioconvers Symp. Indian Institute of Technology, Delhi, India. p 551-71.

Thomas S. 2000. Production of lactic acid from pulp mill solid waste and xylose using Lactobacillus delbrueckii (NRRL B445). Appl Biochem Biotechnol 84-6:455-68. and Professor of Chemical and Environmental Engineering, UC Riverside; and B. Yang was Associate Research Engineer, UC Riverside, and is now Assistant Professor, Center for Bioproducts and Bioenergy, Washington State University. The authors gratefully acknowledge the support of Ford Motor Company and Bourns College of Engineering, UC Riverside. We also thank the U.S. Department of Energy for support of the Biomass Refining Consortium for Applied Fundamentals and Innovation (CAFI), including team research to advance the pretreatment and enzymatic hydrolysis of cellulosic biomass.
[US DOE] US Department of Energy. 1993. Evaluation of a potential wood-to-ethanol process. Washington DC. Rep \#DOE/EP-0004(1/93).

Wood BE, Ingram LO. 1992. Ethanol-production from cellobiose, amorphous cellulose, and crystalline cellulose by recombinant Klebsiella oxytoca containing chromosomally integrated Zymomonas mobilis genes for ethanol production and plasmids expressing thermostable cellulase genes from Clostridium thermocellum. Appl Env Microbiol 58(7):2103-10

Wooley R, Ruth M, Glassner D, Sheehan J. 1999. Process design and costing of bioethanol technology: A tool for determining the status and direction of research and development. Biotechnol Progr 15:794-803.

Wright JD, Wyman CE, Grohmann K. 1987. Simultaneous saccharification and fermentation of lignocellulose: Process evaluation. Appl Biochem Biotechnol 18:75-90.

Wyman CE. 1994. Ethanol from lignocellulosic biomass - technology, economics, and opportunities. Biores Technol 50(1):3-16.

Wyman CE. 1999. Biomass ethanol: Technical progress, opportunities, and commercial challenges. Ann Rev Energy Env 24:189-226.

Wyman CE. 2001. Twenty years of trials, tribulations and research progress in bioethanol technology - selected key events along the way. Appl Biochem Biotechnol 91-3:5-21.

Wyman CE. 2007. What is (and is not) vital to advancing cellulosic ethanol. Trend Biotechnol 25(4):153-7.

Wyman CE, Dale BE, Elander RT, et al. 2005. Coordinated development of leading biomass pretreatment technologies. Biores Technol 96(18):1959-66.

Wyman CE, Goodman BJ. 1993. Near term application of biotechnology to fuel ethanol production from lignocellulosic biomass. In: Busche R (ed.). Opportunities for Innovation in Biotechnology. National Institutes of Standards and Technology, Gaithersburg, MD. p $151-90$

Wyman CE, Spindler DD, Grohmann K, Lastick SM 1986. Simultaneous saccharification and fermentation with the yeast Brettanomyces clausenii. Biotechnol Bioeng Symp 17:221-38.

Yang B, Wyman CE. 2004. Patent application: US 2003-391740 2004185542. Lignin-blocking treatment of biomass and uses thereof.

Yang B, Wyman CE. 2006. BSA treatment to enhance enzymatic hydrolysis of cellulose in lignin containing substrates. Biotechnol Bioeng 94(4):611-7. 